\title{
Tricuspid valve replacement and ventricular septal defect repair in a patient with Glanzmann thrombasthenia
}

\author{
Jake Gillen, BS, ${ }^{\mathrm{a}}$ John Lazarchick, MD, ${ }^{\mathrm{b}}$ and Fred A. Crawford, Jr, MD, ${ }^{\mathrm{c}}$ Charleston, SC
}

We describe the successful replacement of an incompetent tricuspid valve and repair of a ventricular septal defect (VSD) in a patient with Glanzmann thrombasthenia, a congenital defect of platelet aggregation.

\section{CLINICAL SUMMARY}

A 30-year-old woman had symptoms of right-sided heart failure. She had a VSD known since birth and a history of tricuspid valve endocarditis at the age of 17 years, resulting in severe tricuspid insufficiency. During the previous 6 to 12 months, she had noted increasing dyspnea with exertion. Physical examination revealed a 3/6 holosystolic murmur throughout the precordium. Echocardiography revealed a restrictive membranous VSD with 2:1 left-to-right shunt, severe tricuspid regurgitation, and severe right ventricular and right atrial enlargement. Left ventricular ejection fraction was $60 \%$.

The patient was known to have Glanzmann thrombasthenia, a disorder of platelet aggregation. Despite this diagnosis, she had minimal problems with bleeding, with only a single hospitalization for severe epistaxis at the age of 22 years and occasional epistaxis and gingival bleeding since then. She had undergone an ovarian cystectomy at the age of 28 years and received blood and platelet transfusions perioperatively.

Preoperative hematologic workup confirmed the diagnosis and the absence of circulating antiplatelet antibodies despite previous platelet transfusion. The decision was made to proceed with surgery with adequate quantities of platelets available for transfusion.

The patient received 2 units of platelets just before surgery, and standard cardioprotective techniques were used, including heparin anticoagulation and cardiopulmonary bypass with antegrade cold blood potassium cardioplegia. The 10$\mathrm{mm}$ VSD was repaired with a patch. The destroyed tricuspid valve was replaced with a 33-mm Carpentier-Edwards

From the College of Medicine, ${ }^{\mathrm{a}}$ Department of Pathology and Laboratory Medicine, ${ }^{\mathrm{b}}$ and Division of Cardiothoracic Surgery, ${ }^{\mathrm{c}}$ Medical University of South Carolina, Charleston, SC.

Disclosures: None.

Received for publication March 24, 2009; accepted for publication April 11, 2009; available ahead of print June 11, 2009

Address for reprints: Fred A. Crawford, Jr, MD, Division of Cardiothoracic Surgery, Medical University of South Carolina, 25 Courtenay Dr, Suite 7018, MSC 295,

Charleston, SC 29425 (E-mail: crawfrdf@musc.edu).

J Thorac Cardiovasc Surg 2010;139:e114-5

$0022-5223 / \$ 36.00$

Copyright (c) 2010 by The American Association for Thoracic Surgery doi:10.1016/j.jtcvs.2009.04.014 bovine pericardial valve (Edwards Lifesciences, Irvine, Calif). Total cardiopulmonary bypass time was 107 minutes, with an 82-minute crossclamp time. Postoperative echocardiography revealed no intracardiac shunt and a well-seated tricuspid valve without paravalvular leakage. Intraoperative bleeding was not different from that in a patient with normal platelet aggregation. Postoperatively chest tube drainage was $470 \mathrm{~mL}$. The patient received an additional 2 units of platelets on postoperative day 3. Recovery was uncomplicated, and she was discharged on postoperative day 8 .

\section{DISCUSSION}

Glanzmann thrombasthenia is characterized molecularly by a defect in the glycoprotein IIb/IIIa complex on the surface of platelets. This complex binds fibrinogen and other clotting factors and is involved in platelet aggregation. Patients with this disease have normal platelet counts but abnormal platelet function. Their platelets aggregate appropriately in response to ristocetin but not adenosine diphosphate, collagen, epinephrine, or thrombin. This disorder is inherited in an autosomal recessive manner, with increased incidence seen with consanguineous parents. These patients commonly have epistaxis, gingival bleeding, purpura, and menorrhagia. They exhibit easy bruising and prolonged physiologic bleeding, but visceral hemorrhages, hemarthrosis, and spontaneous unprovoked bleeding events are rare. For most patients, the disease has minimal effects on their normal daily lives. ${ }^{1}$

Management of these patients consists primarily of platelet transfusions, either prophylactically before procedures in which bleeding is expected or to help stop an acute bleeding event. Some patients have antiplatelet antibodies develop after repeated transfusions, and their condition becomes refractory to treatment with further transfusions. Recombinant factor VIIa and antifibrinolytic agents have been used with some success in such cases. ${ }^{2}$ Hematopoietic stem cell transplant has also been used for patients with recurrent severe bleeding or resistance to platelet transfusions. ${ }^{3}$

Although there have been numerous reports of patients with Glanzmann thrombasthenia undergoing abdominal, pelvic, orthopedic, and dental surgery, there have only been 2 other reports to our knowledge of affected patients who have undergone cardiac surgery. A 77-year-old woman underwent coronary artery bypass grafting, complicated by cardiac tamponade on postoperative day 2. She was found to be HLA sensitized postoperatively, explaining her marked consumptive thrombocytopenia. ${ }^{4}$ An 8 -year-old boy with Glanzmann thrombasthenia underwent VSD 
repair. Before the operation, he received 6 units of platelets and intravenous desmopressin at $0.3 \mu \mathrm{g} / \mathrm{kg}$ every 2 hours for 4 doses. He was discharged on postoperative day 8 without complications. ${ }^{5}$

Our patient underwent a careful preoperative hematologic workup to rule out antiplatelet antibodies and to match donor platelets for compatibility. She received 2 units of platelets just before the operation and was then monitored carefully for clinical and laboratory signs of coagulopathy. Extra attention was also paid to precise surgical technique. The VerifyNow IIb/IIIa assay (Accumetrics, Inc, San Diego, Calif), typically used to assess levels of functioning platelets in patients treated with glycoprotein IIb/IIIa inhibitors such as abciximab or eptifibatide, was used perioperatively to monitor levels of properly functioning platelets. ${ }^{6}$

We conclude that patients with Glanzmann thrombasthenia are able to undergo heart surgery despite their bleeding diathesis, as long as care is taken in proper preoperative workup to prepare for and avoid potential complications. This was accomplished in our patient through close collaboration of hematology, the blood bank, and the cardiopulmonary bypass team.

\section{References}

1. George JN, Caen JP, Nurden AT. Glanzmann's thrombasthenia: the spectrum of clinical disease. Blood. 1990;75:1383-5.

2. Hennewig U, Laws HJ, Eisert S, Gobel U. Bleeding and surgery in children with Glanzmann thrombasthenia with and without the use of recombinant factor VIIa Klin Padiatr. 2005;217:365-701.

3. Connor P, Khair K, Liesner R, Amrolia P, Veys P, Ancliff P, et al. Stem cell transplantation for children with Glanzmann thrombasthenia. Br J Haematol. 2008;140: 568-71.

4. Ryckman JG, Hall S, Serra J. Coronary artery bypass grafting in a patient with Glanzmann's thrombasthenia. J Card Surg. 2005;20:555-6.

5. Yilmaz BT, Alioglu B, Ozyurek E, Akay HT, Mercan S, Ozbek N. Successful use of recombinant factor VIIa (NovoSeven) during cardiac surgery in a pediatric patient with Glanzmann thrombasthenia. Pediatr Cardiol. 2005;26:843-5.

6. van Werkum JW, Harmsze AM, Elsenberg EH, Bouman HJ, ten Berg JM, Hackeng CM. The use of the VerifyNow system to monitor antiplatelet therapy: a review of current evidence. Platelets. 2008;19:479-88.

\title{
Surviving a transfixing cardiac injury caused by a stingray barb
}

\author{
Michael W. Parra, MD, ${ }^{\mathrm{a}}$ Eugene N. Costantini, MD, FACS, ${ }^{\mathrm{b}}$ Edgar B. Rodas, MD, ${ }^{\mathrm{a}}$ Pedro J. Gonzalez, MD, ${ }^{\mathrm{a}}$ \\ Omar J. Salamen, DDS, ${ }^{c}$ Joseph D. Catino, MD, ${ }^{\mathrm{a}}$ Paul M. Taber, RN, BSN, ${ }^{\mathrm{a}}$ and Ivan Puente, MD, FACS, ${ }^{\mathrm{a}}$ \\ Fort Lauderdale, Fla
}

Stingray injuries have a traumatic component (puncture) and a toxic component (envenomation). Envenomation is generally not lethal but causes intense pain and significant local tissue necrosis. Rare puncture injuries to the thorax or abdomen can cause serious injuries and death. ${ }^{1}$ The following is a description of what we believe to be the first reported survivor of a transfixing cardiac injury caused by a stingray barb.

\section{CLINICAL SUMMARY}

An 81-year-old man was driving his boat when a spotted eagle stingray leaped out of the water, struck his torso, and landed on his lap. The patient was inadvertently stung

\footnotetext{
From the Divisions of Trauma and Critical Care ${ }^{\mathrm{a}}$ and Thoracic and Cardiovascular Surgery, ${ }^{\mathrm{b}}$ Broward General Medical Center; and the Division of Oral Maxillofacial Surgery, ${ }^{\mathrm{c}}$ NOVA Southeastern University, Fort Lauderdale, Fla.

Disclosures: None.

Received for publication Jan 23, 2009; revisions received Feb 12, 2009; accepted for publication Feb 24, 2009; available ahead of print June 1, 2009.

Address for reprints: Michael W. Parra, MD, Division of Trauma Critical Care, Broward General Medical Center/Level I Trauma Center, 1600 S Andrews Ave, Fort Lauderdale, FL 33316 (E-mail: michaelwparra@yahoo.com).

J Thorac Cardiovasc Surg 2010;139:e115-6 0022-5223/\$36.00

Copyright (c) 2010 Published by Elsevier Inc. on behalf of The American Association for Thoracic Surgery

doi:10.1016/j.jtcvs.2009.02.052
}

with the barb in his left chest and was immediately transported to a nearby level II trauma center by emergency medical personnel. Physical examination revealed a 2-mm irregular laceration to the anterior left chest wall just medial and slightly inferior to the corresponding nipple. A computed tomographic scan of the chest showed a $5 \%$ left pneumothorax and a $2-\mathrm{cm}$ linear foreign body penetrating the anterior chest wall. A left anterior thoracotomy and a pericardiotomy were performed in the operating room. After recognizing that the foreign body was intracardiac, the 2 ventricular wall defects were closed with pericardial pledgets for hemorrhage control, and the patient was transferred to our institution. An echocardiogram showed the barb sitting across both the left and right ventricles (Figure 1). The patient was returned to the operating room, and through a median sternotomy, he was started on cardiopulmonary bypass. The right atrium was accessed, and the stingray barb was visualized by means of gentle traction of the posterior leaflet of the tricuspid valve (Figure 2). The barb was removed in an antegrade fashion, pulling it through the free wall of the right ventricle to prevent the barb from causing any additional trauma. The ventricular septum and the right ventricular free wall defects were closed with pledgeted Prolene sutures 